\title{
RESEÑA DE LIBRO: Zellweger, Thomas (2017) Managing the Family Business: Theory and Practice. Edward Elgar Publishing.
}

\author{
Roberto Carlos Dávila Morán* \\ https://orcid.org/0000-0003-3181-8801
}

\begin{abstract}
Como citar: Dávila Morán, Roberto. (2022). Zellweger, Thomas (2017) Managing the Family Business: Theory and Practice. Edward Elgar Publishing. Telos: revista de Estudios Interdisciplinarios en Ciencias Sociales, 24 (1), Venezuela. (Pp. 209-211).

DOI: www.doi.org/10.36390/telos 241.13
\end{abstract}

El libro de Zellweger sirve como un recurso de entrada para el estudio y la práctica de las empresas familiares. Reconoce una brecha en los recursos disponibles que examinan el status quo del conocimiento sobre las empresas familiares y presenta su libro como un medio para ayudar a cerrar esta brecha. Para ello, destaca las estrategias accionables que promueven procesos efectivos y el éxito a largo plazo de las empresas familiares. Las estrategias presentadas en el libro se desarrollan sobre una base amplia. Zellweger se basa en múltiples disciplinas de los negocios, como finanzas, emprendimiento, estrategia, gestión de recursos humanos y marketing.

El libro está dirigido a quienes deseen comprender mejor los desafíos que enfrentan las empresas familiares y las prácticas que pueden emplearse para superarlos. El público objetivo incluye estudiantes y profesionales de la gestión de empresas familiares. El texto se compone de nueve secciones separadas que se centran en temas particularmente comunes y relevantes como la gobernanza o la sucesión. Como resultado, el libro se parece más a una antología que a un libro de texto.

Zellweger establece el tono del texto en la primera sección al distinguir las empresas no familiares de las familiares. Las empresas familiares se definen como una empresa controlada predominantemente por una familia con la visión de mantener potencialmente el control familiar a lo largo de generaciones. Dos puntos temáticos clave planteados en esta definición, el control familiar y las intenciones transgeneracionales, son corrientes subterráneas prominentes que se encuentran a lo largo del libro. El libro muestra un gran interés en las secciones relacionadas con la gobernanza, la estrategia y la sucesión. Estas secciones, además de la sección de apertura que define las empresas familiares, pueden considerarse secciones fundacionales a partir de las cuales Zellweger establece las estrategias accionables para el éxito de las empresas familiares. Por ejemplo, considerando la aplicabilidad restringida de la investigación y la práctica de gobierno corporativo tradicional, Zellweger afirma que las empresas familiares necesitan un sistema de gobierno integrado que entrelaza los dominios de gobierno corporativo, propiedad, familia y patrimonio en un marco coherente.

\footnotetext{
* Universidad Privada del Norte (UPN), Perú. Correo electrónico rdavila430@gmail.com
} 
RESEÑA DE LIBRO: Zellweger, Thomas (2017) Managing the Family Business: Theory and Practice. Edward Elgar Publishing.

Siguiendo el capítulo sobre estrategia, el de sucesión enfatiza que las familias que ingresan a esta fase de transición a menudo quieren cumplir con las metas personales, familiares y de la empresa. Zellweger sostiene que este proceso de cumplimiento de diversos objetivos establece un entorno en el que la toma de decisiones puede estar sesgada por las emociones. Para evitar malas decisiones para la empresa y la familia, el texto analiza varias estrategias, incluidos los seis pasos del marco de sucesión: 1) aclarar metas y prioridades, 2) revisar la estrategia de la empresa, 3) planificar la transición de responsabilidades, 4) valoración de la empresa, 5) financiación de la sucesión y 6) estructuración de la estructura fiscal y jurídica. Zellweger destaca que, si bien los dos primeros pasos son los más críticos, demasiados procesos de sucesión se centran solo en las implicaciones fiscales. Si bien el libro se centra en los resultados financieros y organizativos, es en el capítulo final del texto, cuando Zellweger también dedica algún tiempo a cómo manejar las relaciones familiares y los conflictos.

En conjunto, el libro se parece más a una antología que a un libro de texto, ya que se mueve a través de las nueve secciones que cubren temas importantes, pero sin fuertes conexiones entre ellos. Este punto no es tanto una debilidad del libro sino una reflexión sobre la naturaleza de la investigación que se centra en temas aislados. Dicho esto, Zellweger podría haber agregado una conclusión a su libro para construir puentes más sólidos entre sus capítulos y enfatizar las conclusiones.

En todos los capítulos, Zellweger debe ser aplaudido por derivar estrategias viables para la gestión exitosa de empresas familiares. Solo hay algunas advertencias. Primero, el enfoque de Zellweger para desarrollar recomendaciones es de naturaleza positivista y un supuesto importante es la existencia de mercados eficientes. Por ejemplo, da a entender que existe una gobernanza eficaz y que puede ser una solución a los malestares de las empresas familiares. En su defensa, Zellweger es consciente de las limitaciones de los mercados eficientes y la gobernanza formal. Esto se vuelve obvio cuando analiza la perspectiva de la paradoja y explica que, si bien rara vez existen claras compensaciones entre la familia y la empresa, muchos estudios se centran en explicaciones simples en blanco y negro que ignoran la complejidad subyacente de estos sistemas. En segundo lugar, Zellweger se centra implícitamente en empresas familiares bastante grandes de países desarrollados. Por ejemplo, los estudios de caso al final de cada capítulo provienen de países de Europa occidental y los EE. UU. Y, a menudo, describen empresas familiares medianas o grandes de larga duración. En tercer lugar, todavía no se han estudiado suficientemente todas las recomendaciones que hace Zellweger. Sin embargo, considerando la falta de investigación sobre muchos temas emergentes como la gobernanza patrimonial y los argumentos lógicos que ofrece Zellweger, es justo decir que sus recomendaciones son sugerencias plausibles, especialmente para empresas familiares medianas o grandes en los países occidentales.

En general, Zellweger saca hábilmente puntos importantes de discusiones académicas sobre varios temas. Debido a que estas discusiones son a veces densas y se caracterizan por la jerga académica, el texto puede estar ligeramente inclinado hacia una audiencia académica. Sin embargo, los profesionales apreciarán el final de cada capítulo, donde hay recursos tangibles y herramientas pedagógicas como los estudios de casos y preguntas de reflexión. Estos recursos son aplicables y seleccionados adecuadamente para cerrar la brecha entre lo teórico y lo práctico. Sin embargo, un mayor enfoque en estos complementos podría haber hecho que el libro fuera aún más relevante para los empresarios y profesionales. Tal como está, el libro podría 
llegar a ser más popular entre los profesores que imparten cursos de negocios familiares y los estudiantes graduados interesados en los negocios familiares.

En resumen, el texto llena efectivamente una gran brecha en los recursos disponibles sobre las empresas familiares y comienza un discurso interesante que destaca los desafíos comunes de las empresas familiares y las estrategias disponibles para abordarlos. Es probable que este libro se convierta en otro recurso importante que dé forma al panorama de la erudición en empresas familiares. Si bien los libros icónicos anteriores han proporcionado información inmensamente importante sobre el desarrollo de la empresa familiar a través de generaciones y las características de las grandes empresas familiares multigeneracionales exitosas, Zellweger se encuentra entre los primeros en ofrecer suficiente profundidad en una serie de temas centrales para empresas familiares. Su libro es un aporte oportuno y relevante que muchos han estado esperando y disfrutarán. De cara al futuro, su texto también podría convertirse en un recurso de entrada para otros que escriban sobre cómo administrar la familia (empresarial) en lugar de la empresa familiar.

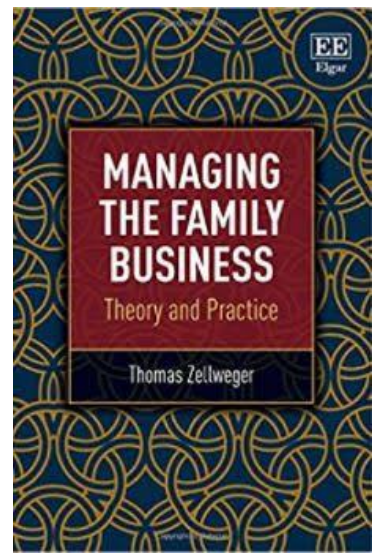

